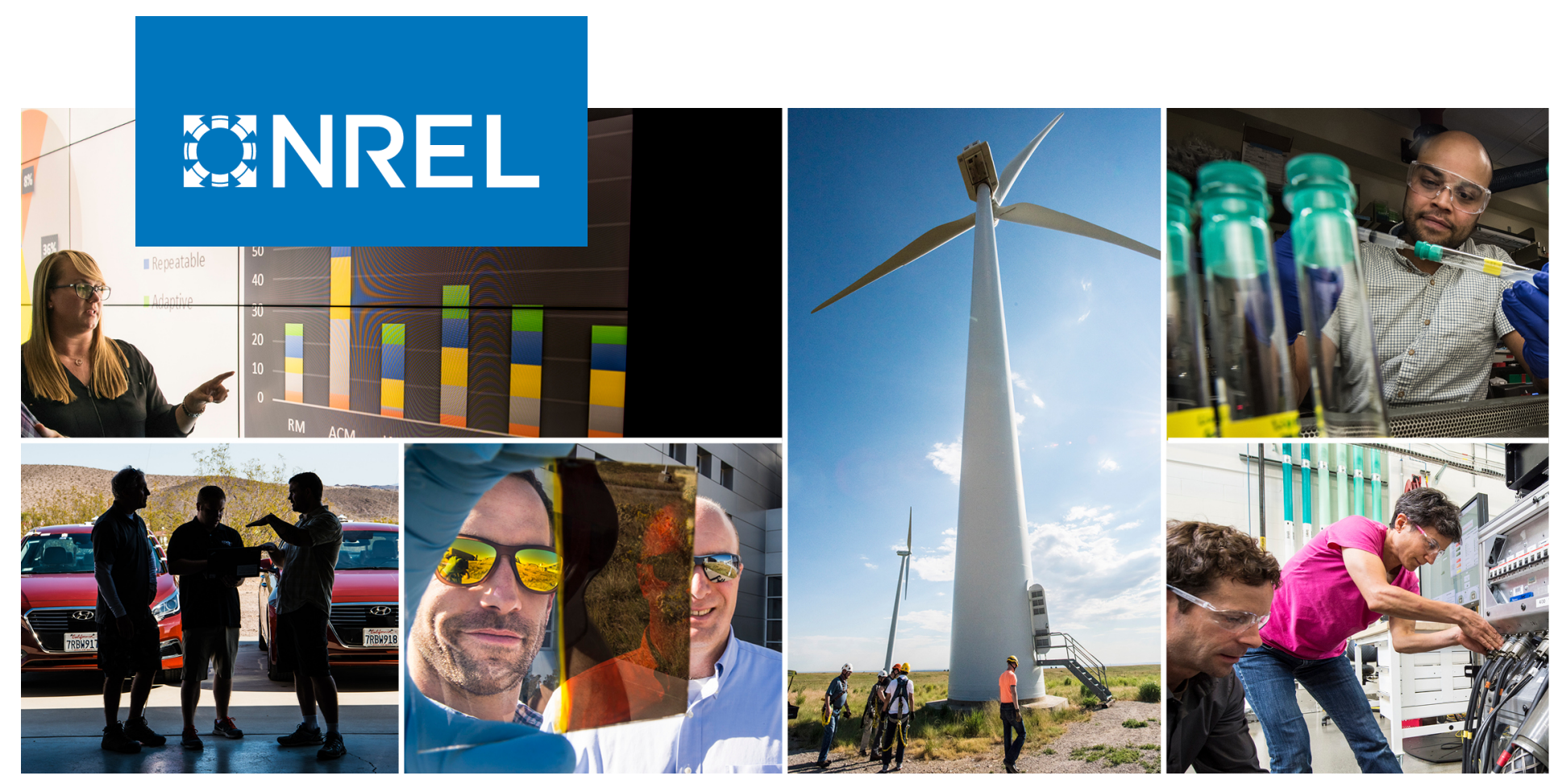

\title{
Progress on the National Solar Radiation Data Base (NSRDB): A New DNI Computation
}

\section{Preprint}

Yu Xie, ${ }^{1}$ Manajit Sengupta, ${ }^{1}$ Yangang Liu, ${ }^{2}$ Hai Long, ${ }^{1}$ and Aron Habte ${ }^{1}$

1 National Renewable Energy Laboratory
${ }_{2}^{2}$ Brookhaven National Laboratory

Presented at the 47th IEEE Photovoltaic Specialists Conference (PVSC-47) June 15-August 21, 2020

NREL is a national laboratory of the U.S. Department of Energy Office of Energy Efficiency \& Renewable Energy

Operated by the Alliance for Sustainable Energy, LLC

This report is available at no cost from the National Renewable Energy Laboratory (NREL) at www.nrel.gov/publications.
Conference Paper

NREL/CP-5D00-75911

September 2020 


\title{
GHREL
}

\section{Progress on the National Solar Radiation Data Base (NSRDB): A New DNI Computation}

\section{Preprint}

\author{
Yu Xie, ${ }^{1}$ Manajit Sengupta, ${ }^{1}$ Yangang Liu, ${ }^{2}$ Hai Long,,${ }^{1}$ \\ and Aron Habte ${ }^{1}$ \\ ${ }^{1}$ National Renewable Energy Laboratory \\ ${ }^{2}$ Brookhaven National Laboratory
}

\section{Suggested Citation}

Xie, Yu, Manajit Sengupta, Yangang Liu, Hai Long, and Aron Habte. 2020. Progress on the National Solar Radiation Data Base (NSRDB): A New DNI Computation: Preprint. Golden, CO: National Renewable Energy Laboratory. NREL/CP-5D00-75911. https://www.nrel.gov/docs/fy20osti/75911.pdf.

(C) 2020 IEEE. Personal use of this material is permitted. Permission from IEEE must be obtained for all other uses, in any current or future media, including reprinting/republishing this material for advertising or promotional purposes, creating new collective works, for resale or redistribution to servers or lists, or reuse of any copyrighted component of this work in other works.

NREL is a national laboratory of the U.S. Department of Energy Office of Energy Efficiency \& Renewable Energy Operated by the Alliance for Sustainable Energy, LLC

This report is available at no cost from the National Renewable Energy Laboratory (NREL) at www.nrel.gov/publications.

Contract No. DE-AC36-08GO28308
Conference Paper

NREL/CP-5D00-75911

September 2020

National Renewable Energy Laboratory 15013 Denver West Parkway Golden, CO 80401

303-275-3000 • www.nrel.gov 


\section{NOTICE}

This work was authored in part by the National Renewable Energy Laboratory, operated by Alliance for Sustainable Energy, LLC, for the U.S. Department of Energy (DOE) under Contract No. DE-AC36-08GO28308. Funding provided by U.S. Department of Energy Office of Energy Efficiency and Renewable Energy Solar Energy Technologies Office. The views expressed herein do not necessarily represent the views of the DOE or the U.S. Government.

This report is available at no cost from the National Renewable Energy Laboratory (NREL) at www.nrel.gov/publications.

U.S. Department of Energy (DOE) reports produced after 1991 and a growing number of pre-1991 documents are available free via www.OSTI.gov.

Cover Photos by Dennis Schroeder: (clockwise, left to right) NREL 51934, NREL 45897, NREL 42160, NREL 45891, NREL 48097, NREL 46526.

NREL prints on paper that contains recycled content. 


\title{
Progress on the National Solar Radiation Data Base (NSRDB): A new DNI computation
}

\author{
Yu Xie \\ National Renewable Energy \\ Laboratory \\ Golden, CO, USA \\ yu.xie@nrel.gov
}

\author{
Manajit Sengupta \\ National Renewable Energy \\ Laboratory \\ Golden, CO, USA \\ manajit.sengupta@nrel.gov
}

\author{
Yangang Liu \\ Brookhaven National \\ Laboratory \\ Upton, NY, USA \\ lyg@bnl.gov
}

\author{
Hai Long \\ National Renewable Energy \\ Laboratory \\ Golden, CO, USA \\ hai.long@nrel.gov
}

\author{
Aron Habte \\ National Renewable Energy \\ Laboratory \\ Golden, CO, USA \\ aron.habte@nrel.gov
}

\begin{abstract}
This study introduces a new technique to compute direct normal irradiance (DNI) for improving the National Solar Radiation Data Base (NSRDB). A finite-surface integration algorithm is developed to compute solar radiation in differential solid angles and efficiently infer its contribution to a surface perpendicular to the solar direction. A lookup table of cloud bi-directional transmittance distribution function (BTDF) is developed by use of the discrete ordinates radiative transfer (DISORT) model for possible solar and observing directions and various cloud optical and microphysical properties. In each solar incident direction, DNI is given by the cloud BTDFs from approximately 200 differential solid angles. The simulated DNI is calibrated and evaluated using surface observations at the National Renewable Energy Laboratory's (NREL's) Solar Energy Research Laboratory (SRRL) and the Atmospheric Radiation Measurement (ARM) Southern Great Plains (SGP) facility.
\end{abstract}

Keywords—solar radiation, DNI, NSRDB, radiance.

\section{INTRODUCTION}

Direct Normal Irradiance (DNI) representing solar radiation received by a surface that is perpendicular to the straight line from the direction of the sun is often used to assess the solar resource and is particularly crucial in evaluating the performance of concentrating solar power (CSP) systems [1]. Numerous radiative transfer models assume that DNI is related to a narrow beam covering only the solar disk where the Lambert-Bouguer law is used in the numerical computation of DNI [2]. However, DNI is often interpreted differently in solar observation by pyrheliometers [3-6]. For example, the ISO-9488 standard defines direct irradiance by "the quotient of the radiant flux on a given plane receiver surface received from a small solid angle centered on the sun's disk to the area of that surface." This indicates that the circumsolar diffuse radiation might affect the accuracy of DNI computed by the radiative transfer models. This study seeks to improve the National Renewable Energy Laboratory's (NREL's) National Solar Radiation Data Base (NSRDB) by computing circumsolar radiation and understanding its impact on the numerical simulation of DNI in various cloud conditions.

\section{COMPUTATION OF DNI}

Figure 1 shows a flowchart of the algorithm to compute DNI for clear- and cloudy-sky conditions. For clear-sky conditions, the atmospheric and land surface properties - e.g., the amount of precipitable water vapor (PWV), the concentration of carbon dioxide, surface pressure, and land surface albedo-from surface or satellitebased observations are used by a radiative transfer model designed for cloudless scenarios to calculate DNI [7]. For cloudy-sky conditions, the direct radiation is computed by considering three components: the direct radiation in an infinite-narrow beam, the first-order diffuse radiation in the circumsolar region, and multiple reflection between cloud and land surface that falls into the circumsolar region.

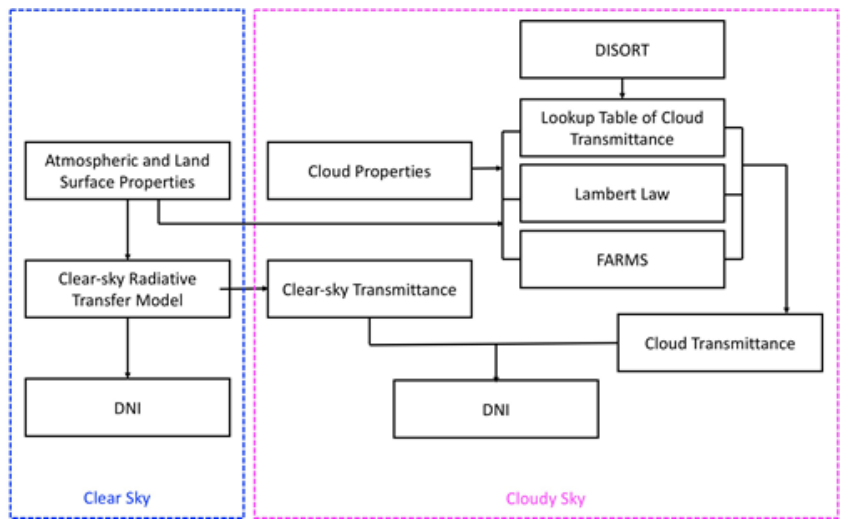

Figure 1 Flowchart of the computation of DNI in clear- and cloudy-sky conditions.

Figure 2 demonstrates the three components of the DNI. According to the Beer-Bouguer-Lambert law, the direct radiation in the infinite-narrow beam can be given by

$$
\mathrm{DNI}_{\mathrm{d} 0}=\mathrm{F}_{0} \mathrm{~T}_{\mathrm{dd}}^{\mathrm{clr}} \exp \left(-\frac{\tau}{\mu_{0}}\right)
$$


where $\mathrm{F}_{0}$ is the extraterrestrial solar radiation, $\tau$ is the cloud optical thickness, and $\mathrm{T}_{\mathrm{dd}}^{\mathrm{clr}}$ is the transmittance of direct radiation in the clear atmosphere.

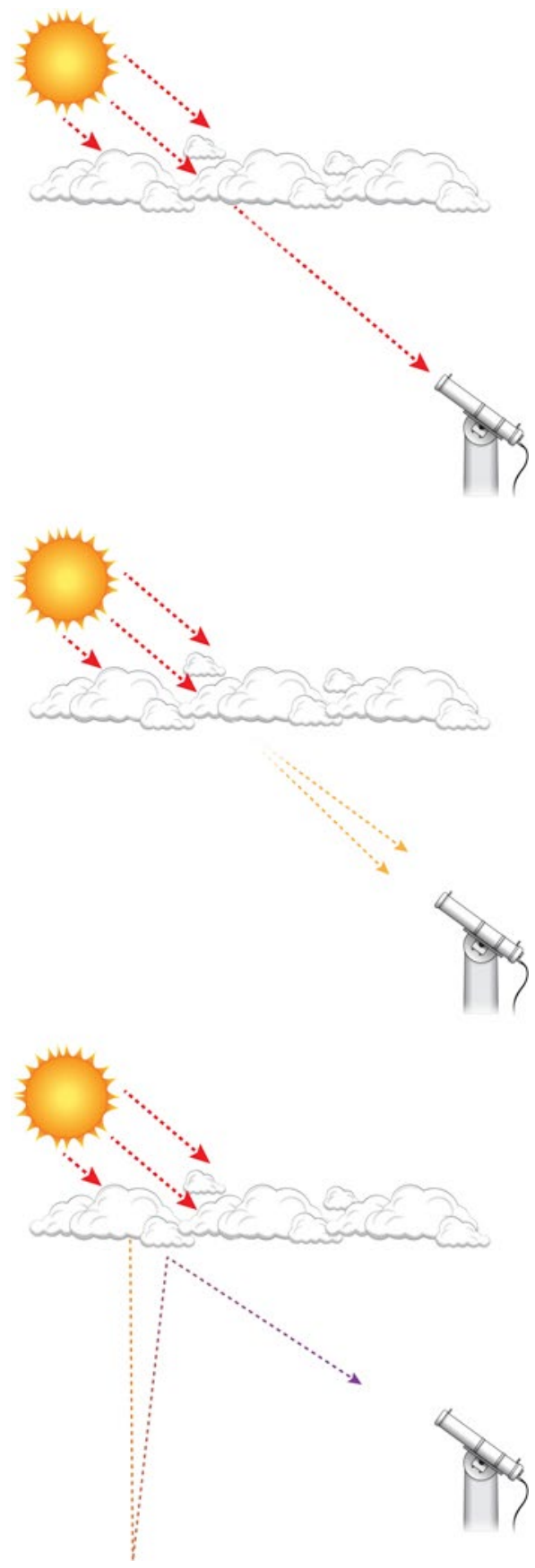

Figure 2 The direct radiation in an infinite-narrow beam (upper), the first order diffuse radiation in the circumsolar region (middle), and multiple reflection between cloud and land surface that falls into the circumsolar region (lower).

The first-order diffuse radiation in the circumsolar region can be computed by

$$
\mathrm{DNI}_{\mathrm{d} 1}=\mathrm{F}_{0} \mathrm{~T}_{\mathrm{dd}}^{\mathrm{clr}} \mathrm{T}_{\mathrm{dd}}^{\mathrm{cld}}
$$

where $\mathbf{T}_{\mathbf{d d}}^{\text {cld }}$ is the cloud transmittance of the first order direct radiation that can be computed by the 64-stream discrete ordinates radiative transfer (DISORT) model [8]. The multiple reflection between cloud and land surface that falls into the circumsolar region can be given as follows:

$$
\mathrm{DNI}_{\mathrm{d} 2}=\frac{1}{\mu_{0}} \iint_{\Omega\left(\theta_{0}\right)} \mathrm{I}_{2} \cos \theta \sin \theta \mathrm{d} \theta \mathrm{d} \varphi
$$

where $\boldsymbol{\mu}_{\mathbf{0}}$ is the cosine value of the solar zenith angle, $\boldsymbol{\Omega}\left(\boldsymbol{\theta}_{\mathbf{0}}\right)$ is the solid angle related to the circumsolar region, $\boldsymbol{\theta}_{\mathbf{0}}$ is the solar zenith angle, $\boldsymbol{\theta}$ is zenith angle, and $\boldsymbol{\varphi}$ is the azimuth angle. $\mathbf{I}_{\mathbf{2}}$ is the radiance of the solar radiation related to the multiple reflection between the cloud and land surface. In this study, $\mathbf{I}_{2}$ is computed by the Fast All-sky Radiation Model for Solar applications (FARMS) [9-13] by assuming isotropic reflection of solar radiation by the land surfaces [14].

\section{CONCLUSIONS}

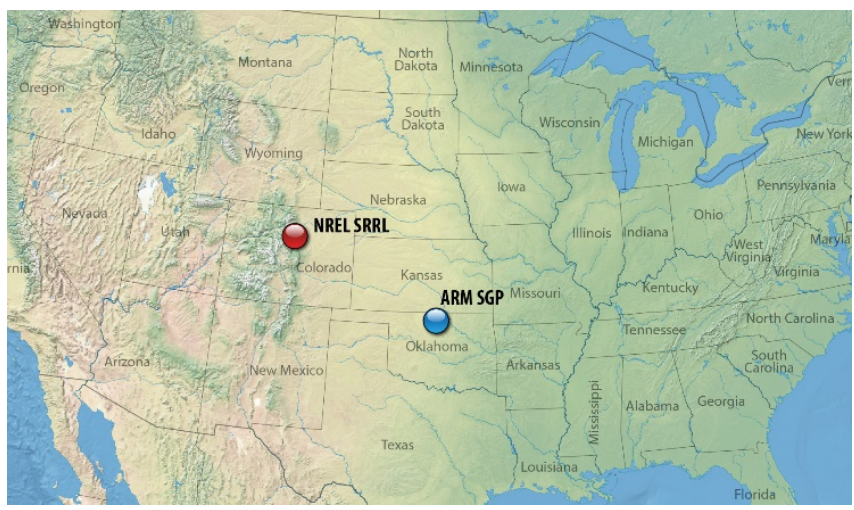

Figure 3 NREL SRRL and ARM SGP sites that are used to validate the new DNI model.

To validate the new DNI model, we employed long-term data from surface-based measurements at National Renewable Energy Laboratory's (NREL's) Solar Radiation Research Laboratory (SRRL) (Fig. 3). The 1-minute resolution cloud fraction, surface pressure, surface albedo, and solar zenith angle from September 1, 2008 to January 27, 2019 are utilized to compute DNI. With the assumption of a homogenous water cloud layer when the observed cloud fraction is greater than 0.95 , the cloud optical thickness is estimated by the GHI measurement and FARMS using a variety of cloud optical thicknesses. The observations from January 2, 1998 to December 31, 2014 at the Atmospheric Radiation Measurement (ARM) Southern Great Plains (SGP) facility are also used in the validation (Fig. 3). Our results show that the percentage error (PE) for water clouds has been reduced from $74.98 \%$ to $22.93 \%$ by using the new DNI model. For ice clouds, the PE has been reduced from $78.85 \%$ to $44.15 \%$. The new DNI model will be used in the future updates of the NSRDB.

\section{ACKNOWLEDGEMENTS}

This work was authored in part by the National Renewable Energy Laboratory, operated by the Alliance for Sustainable Energy, LLC, for the U.S. Department of Energy Office (DOE) under Contract No. DE-AC36-08GO28308. Funding 
provided by U.S. Department of Energy Office of Energy Efficiency and Renewable Energy Solar Energy Technologies Office. The Brookhaven National Laboratory is operated by the Brookhaven Science Associates, LLC (BSA), for the U.S. Department of Energy under Contract No. DE-SC0012704. The views expressed in the article do not necessarily represent the views of the Department of Energy or the U.S. Government. The U.S. Government retains and the publisher, by accepting the article for publication, acknowledges that the U.S. Government retains a nonexclusive, paid-up, irrevocable, worldwide license to publish or reproduce the published form of this work, or allow others to do so, for U.S. Government purposes.

This research was performed using computational resources sponsored by the Department of Energy's Office of Energy Efficiency and Renewable Energy and located at the National Renewable Energy Laboratory.

\section{REFERENCES}

[1] M. Sengupta, Y. Xie, A. Lopez, A. Habte, G. Maclaurin, and J. Shelby, "The National Solar Radiation Data Base (NSRDB)," Renew. Sustain. Energy Rev., vol. 89, pp. 51-60, 2018.

[2] K. N. Liou, An introduction to atmospheric radiation, 2nd ed. Amsterdam; Boston: Academic Press, 2002, p. 583.

[3] P. Blanc et al., "Direct normal irradiance related definitions and applications: The circumsolar issue," Sol. Energy, vol. 110, pp. 561-577, 2014.

[4] Y. Xie and Y. G. Liu, "A new approach for simultaneously retrieving cloud albedo and cloud fraction from surface-based shortwave radiation measurements," Environ. Res. Lett., vol. 8, pp. doi:10.1088/1748-9326/8/4/044023, 2013.

[5] Y. Xie, Y. G. Liu, C. N. Long, and Q. L. Min, "Retrievals of cloud fraction and cloud albedo from surface-based shortwave radiation measurements: A comparison of 16 year measurements," $J$. Geophys. Res. Atmos., vol. 119, no. 14, pp. 8925-8940, Jul 27 2014.

[6] N. Hanrieder, M. Sengupta, Y. Xie, S. Wilbert, and R. Pitz-Paal, "Modeling beam attenuation in solar tower plants using common DNI," Sol. Energy, vol. 129, pp. 244-255, 2016.

[7] C. Gueymard, "SMARTS2: a simple model of the atmospheric radiative transfer of sunshine: algorithms and performance assessment," Florida Solar Energy Center, vol. Cocoa, FL, 1995.

[8] K. Stamnes, S. C. Tsay, W. Wiscombe, and K. Jayaweera, "Numerically stable algorithm for discrete-ordinate-method radiative transfer in multiple scattering and emitting layered media," Appl. Opt., vol. 27, no. 12, pp. 2502-2509, Jun 151988.

[9] Y. Xie, M. Sengupta, and J. Dudhia, "A Fast All-sky Radiation Model for Solar applications (FARMS): Algorithm and performance evaluation," Sol. Energy, vol. 135, pp. 435-445, 2016.

[10] Y. Xie, M. Sengupta, and M. Dooraghi, "Assessment of uncertainty in the numerical simulation of solar irradiance over inclined PV panels: New algorithms using measurements and modeling tools," Sol. Energy, vol. 165, pp. 55-64, 2018.

[11] Y. Xie and M. Sengupta, "A Fast All-sky Radiation Model for Solar applications with Narrowband Irradiances on Tilted surfaces (FARMS-NIT): Part I. The clear-sky model," Sol. Energy, vol. 174, pp. 691-702, 2018.

[12] Y. Xie, M. Sengupta, and C. Wang, "A Fast All-sky Radiation Model for Solar applications with Narrowband Irradiances on Tilted surfaces (FARMS-NIT): Part II. The cloudy-sky model," Sol. Energy, vol. 188, pp. 799-812, 2019.
[13] Y. Xie et al., "A physics-based DNI model assessing all-sky circumsolar radiation," iScience, vol. 22, p. doi.org/10.1016/j.isci.2020.100893, 2020.

[14] C. Gueymard, V. Lara-Fanego, M. Sengupta, and Y. Xie, "Surface albedo and reflectance: Review of definitions, angular and spectral effects, and intercomparison of major data sources in support of advanced solar irradiance modeling over the Americas," Sol. Energy, vol. 182, pp. 194-212, 2019. 